288 HENDERSON AND HEILBRON : CONTRIBUTIONS TO THE

XXVII.-Contributions to the Chemistry of the Terpenes. Part III. Sone Oxidation Products of Pinene.

By George Gerald Henderson and Isidore Morris Heilbron.

THe additive compound $\mathrm{C}_{10} \mathrm{H}_{16}, 2 \mathrm{CrO}_{2} \mathrm{Cl}_{2}$, which is formed by the action of chromyl chloride on pinene under suitable conditions (Henderson and Gray, Trans., 1903, 83, 1299), yields when decomposed by water a saturated aldehyde, an unsaturated ketone, and a small quantity of a chlorinated oxidation product, together with much resinous matter. The aldehyde is easily converted into the corresponding acid, and, as it was found that a bromo-derivative of this could not be obtained by direct bromination, the chloride, $\mathrm{C}_{9} \mathrm{H}_{15} \cdot \mathrm{COCl}$, was prepared from the acid. This chloride is a heavy, oily liquid, which reacts readily with water, and when heated with bromine under pressure is converted easily and completely into the bromo-derivative, $\mathrm{C}_{9} \mathrm{H}_{14} \mathrm{Br} \cdot \mathrm{COCl}$. This compound is very similar in properties to the chloride, and is decomposed by water with formation of the crystalline bromo-acid, $\mathrm{C}_{9} \mathrm{H}_{14} \mathrm{Br}^{\cdot} \mathrm{CO}_{2} \mathrm{H} . \quad$ When boiled with aqueous sodium carbonate, the bromo-acid is converted into the corresponding hydroxy-acid, $\mathrm{C}_{9} \mathrm{H}_{14}(\mathrm{OH}) \cdot \mathrm{CO}_{2} \mathrm{H}$, which crystallises in needles and is soluble, although not readily, in water. Its sodium salt is readily, and its silver salt very sparingly, soluble in water.

When the impure bromo-acid, prepared by the action of water on its chloride, was treated with cold aqueous sodium carbonate, there remained undissolved a small quantity of a neutral compound which 
contains both bromine and oxygen. It crystallises from alcohol in small, colourless prisms, and appears to have the composition represented by the formula $\mathrm{C}_{10} \mathrm{H}_{13} \mathrm{OBr}$.

The crude hydroxy-acid, precipitated by addition of dilute sulphuric acid to the alkaline solution obtained by heating the bromo-acid with sodium carbonate, was heated with water. The hydroxy-acid passed into solution, but a small quantity of another acid was left undissolved. This acid, of which the formula is probably $\mathrm{C}_{10} \mathrm{H}_{14} \mathrm{O}_{2}$, crystallises from alcohol in silvery leaflets. Its silver salt crystallises from water in small, colourless needles.

The ketone described in the former paper on this subject (loc. cit.), to which the formula $\mathrm{C}_{10} \mathrm{H}_{14} \mathrm{O}$ was provisionally assigned, has now been obtained in a purer state, and has been found to have the formula $\mathrm{C}_{9} \mathrm{H}_{14} \mathrm{O}$. When reduced with sodium and alcohol, it yields the alcohol, $\mathrm{C}_{9} \mathrm{H}_{15} \cdot \mathrm{OH}$, a viscous, colourless liquid, almost insoluble in water, but freely soluble in alcohol or ether. Its phenylurethane crystallises in delicate, colourless needles, and its acid phthalic ester in lustrous leaflets.

When heated with ammonium formate, the ketone is converted chiefly into the formyl derivative of an amine. The free anine, $\mathrm{C}_{9} \mathrm{H}_{15} \cdot \mathrm{NH}_{2}$, is a colourless, oily liquid with a strong, disagreeable odour, and is almost insoluble in water. Its hydrochloride crystallises in silky needles which are extremely easily soluble in water, and its platinichloride is obtained in yellow leaflets.

The chlorinated oxidation product, separated from the ketone by repeated fractional distillations under diminished pressure, has the formula $\mathrm{C}_{10} \mathrm{H}_{15} \mathrm{OCl}$. It crystallises from light petroleum in small prisms, and decomposes when heated above its melting point. It is very readily soluble in the usual organic solvents, and is not decomposed when heated with water. It does not yield an oxime or a semicarbazone, and when treated with sodium and alcohol it is slowly converted into a crystalline, strongly odorous compound which does not contain chlorine.

It is to be hoped that further investigation will throw light on the question of the constitution of the compounds described; in the meantime, it would hardly be profitable to indulge in speculation on the subject.

\section{EXPERIMENTA L.}

Preparation of the Hydroxy-Acid, $\mathrm{C}_{9} \mathrm{H}_{14}(\mathrm{OH}) \cdot \mathrm{CO}_{2} \mathrm{H}$.

The calculated quantity of phosphorus pentachloride was mixed with light petroleum, and the dry, finely-powdered acid, $\mathrm{C}_{9} \mathrm{H}_{15} \cdot \mathrm{CO}_{2} \mathrm{H}$, was added in small quantities at a time. The mixture was left for some hours at the ordinary temperature and then heated on the water-bath 
under a reflux condenser until the action was completed. The light petroleum was evaporated, and the residue was then fractionally distilled under diminished pressure. The chloride of the acid was thus obtained in a purified state.

The chloride, $\mathrm{C}_{9} \mathrm{H}_{15} \cdot \mathrm{COCl}$, is a colourless, somewhat viscous liquid, which boils at about $130^{\circ}$ at $30 \mathrm{~mm}$. pressure. It is denser than water and has a peculiar, but not unpleasant odour. It undergoes rapid decomposition when exposed to moist air, and is quickly converted into the corresponding acid by the action of cold water.

The bromo-derivative, $\mathrm{C}_{9} \mathrm{H}_{14} \mathrm{Br} \cdot \mathrm{COCl}$, was prepared by heating the chloride with a slight excess of bromine in a sealed tube at $100^{\circ}$ for about twenty-four hours. This derivative is also a liquid, very similar in appearance to the chloride, and it reacts readily with water.

In order to prepare the corresponding acid, the bromo-derivative was poured into water, and the mixture was well stirred until all the oily compound was decomposed. The crystalline solid was collected, and treated with a cold aqueous solution of sodium carbonate. A small quantity of a solid which did not pass into solution was removed by filtration, the filtrate was acidified, and the bromo-acid which separated was purified by recrystallisation from dilute alcohol.

The bromo-acid, $\mathrm{C}_{9} \mathrm{H}_{14} \mathrm{Br}^{\circ} \cdot \mathrm{CO}_{2} \mathrm{H}$, crystallises in small, colourless prisms. It is very readily soluble in alcohol or ether, and rather sparingly so in water.

The hydroxy-acid was obtained by boiling the bromo-acid with an aqueous solution of sodium carbonate for some hours under a reflux condenser. The solution was then concentrated, cooled, acidified with sulphuric acid, and shaken several times with ether. The ethereal solution was washed with water and dried with calcium chloride, the ether distilled off, and the residue was heated with water. Most of it passed into solution, but a small portion remained undissolved, and was separated by filtration; from the filtrate, on cooling, the hydroxy-acid separated in a crystalline state, and was purified by several crystallisations from water.

The hydroxy-acid, $\mathrm{C}_{9} \mathrm{H}_{14}(\mathrm{OH}) \cdot \mathrm{CO}_{2} \mathrm{H}$, crystallises in small, colourless prisms, which melt at $227^{\circ}$. It is extremely easily soluble in alcohol, fairly so in water, and almost insoluble in light petroleum. When heated with insufficient water for solution, it melts and forms oily drops :

0.1884 gave $0.4486 \mathrm{CO}_{2}$ and $0.1520 \mathrm{H}_{2} \mathrm{O} . \quad \mathrm{C}=64.9 ; \mathrm{H}=8.9$.

$0.1668,0.3956 \mathrm{CO}_{2}, 0.1305 \mathrm{H}_{2} \mathrm{O} . \mathrm{C}=64.8 ; \mathrm{H}=8.7$. $\mathrm{C}_{10} \mathrm{H}_{16} \mathrm{O}_{3}$ requires $\mathrm{C}=65 \cdot 2 ; \mathrm{H}=8 \cdot 7$ per cent.

The sodium salt forms colourless crystals, which are readily soluble in water; the silver salt is obtained as a sparingly soluble, white, crystalline precipitate. 
When boiled with lead peroxide and a little water, the hydroxy-acid does not yield a ketone, but is converted into the lead salt of another acid, of which the quantity available was too small to permit of examination.

The crystalline compound, which was produced along with the bromo-acid and was separated from the latter by its insolubility in cold aqueous sodium carbonate, was purified by crystallisation from alcohol. It crystallises in minute, colourless prisms, which melt at $173^{\circ}$, and is rather sparingly soluble in alcohol and insoluble in water. It is neutral in character, and on analysis it gave results which correspond fairly with those demanded by the formula $\mathrm{C}_{10} \mathrm{H}_{13} \mathrm{OBr}$ :

0.2476 gave $0.4710 \mathrm{CO}_{2}$ and $0.1332 \mathrm{H}_{2} \mathrm{O} . \mathrm{C}=51.9 ; \mathrm{H}=6.0$.

$0 \cdot 1862,0 \cdot 1524 \mathrm{AgBr}$. $\mathrm{Br}=34 \cdot 8$.

$\mathrm{C}_{10} \mathrm{H}_{13} \mathrm{OBr}$ requires $\mathrm{C}=52.4 ; \mathrm{H}=5 \cdot 7 ; \mathrm{Br}=34.9$ per cent.

Owing to the small quantity in our hands, we were not able to examine this compound more fully.

As stated above, another acid is formed in small quantity along with the hydroxy-acid when the bromo-acid is boiled with aqueous sodium carbonate. This acid was easily separated from the hydroxy-acid, as it is insoluble in water, and was purified by crystallisation from alcohol, in which it is rather sparingly soluble. It forms silvery leaflets, which melt at $144^{\circ}$, and it appears to have the composition $\mathrm{C}_{10} \mathrm{H}_{14} \mathrm{O}_{2}$ :

0.1200 gave $0.3164 \mathrm{CO}_{2}$ and $0.0956 \mathrm{H}_{2} \mathrm{O} . \quad \mathrm{C}=71.9 ; \mathrm{H}=8.8$. $\mathrm{C}_{10} \mathrm{H}_{14} \mathrm{O}_{2}$ requires $\mathrm{C}=72.3 ; \mathrm{H}=8.4$ per cent.

The silver salt of this acid crystallises from water, in which it is very sparingly soluble, in colourless needles :

0.0680 gave $0.0268 \mathrm{Ag}$. $\mathrm{Ag}=39 \cdot 4$. $\mathrm{C}_{10} \mathrm{H}_{13} \mathrm{O}_{2} \mathrm{Ag}$ requires $\mathrm{Ag}=39 \cdot 6$ per cent.

\section{The Ketone, $\mathrm{C}_{9} \mathrm{H}_{14} \mathrm{O}$.}

Owing to the difficulties met with in purifying the small quantity of the substance then at our disposal, the analyses of the ketone quoted in the first paper on this subject (loc. cit.), which pointed to the formula $\mathrm{C}_{10} \mathrm{H}_{14} \mathrm{O}$, were open to suspicion, even although the determinations of the percentage of nitrogen in its semicarbazone also supported that formula. By the oxidation of fresh quantities of pinene, a larger supply of the ketone was obtained, and was first purified in the manner already described, and then repeatedly distilled, first under diminished and ultimately at atmospheric pressure, until a fraction of quite constant boiling point was separated. The pure ketone thus obtained boils at $209-210^{\circ}$ under a pressure of $757 \mathrm{~mm}$. A number of closelyagreeing analyses, of which two are quoted below, showed that the formula of the ketone is $\mathrm{C}_{9} \mathrm{H}_{14} \mathrm{O}$ : 


$$
\begin{gathered}
0.1503 \text { gave } 0.4304 \mathrm{CO}_{2} \text { and } 0.1400 \mathrm{H}_{2} \mathrm{O} . \quad \mathrm{C}=78.1 ; \mathrm{H}=10.3 \text {. } \\
0.1612, \quad 0.4608 \mathrm{CO}_{2} \text { and } 0.1528 \mathrm{H}_{2} \mathrm{O} . \quad \mathrm{C}=78.0 ; \mathrm{H}=10.5 \text {. } \\
\mathrm{C}_{9} \mathrm{H}_{14} \mathrm{O} \text { requires } \mathrm{C}=78.3 ; \mathrm{H}=10.1 \text { per cent. }
\end{gathered}
$$

Determinations of the molecular weight of the ketone by the cryoscopic method gave similar results :

0.2350 in 30.32 acetic acid gave $\Delta t-0.22^{\circ}$. Mol. wt. $=136$.

$$
0 \cdot 1635,27 \cdot 83 \quad \mathrm{C}_{9} \ddot{H}_{14} \mathrm{O} \text { requires Mol. wt. }=138 \text {. } "=134 \text {. }
$$

The semicarbazone of the ketone, it is true, was found to contain only 20.5 per cent. of nitrogen, whilst a semicarbazone of the formula $\mathrm{C}_{10} \mathrm{H}_{17} \mathrm{ON}_{3}$ should contain 21.5 per cent. On the other hand, the analysis of the alcohol obtained by reduction of the ketone confirms the conclusion that the formula of the latter is $\mathrm{C}_{9} \mathrm{H}_{14} \mathrm{O}$.

\section{Preparation of the Alcohol, $\mathrm{C}_{9} \mathrm{H}_{15} \cdot \mathrm{OH}$.}

A solution of the ketone in alcohol was heated to boiling under a reflux condenser, and twice the theoretical quantity of sodium was gradually added. The liquid after cooling was mixed with water and almost completely neutralised with acetic acid, and the bulk of the alcohol was then distilled off. The residual liquid was shaken several times with ether, and the ethereal solution was washed with water and dried with anhydrous magnesium sulphate. After removal of the ether by distillation, the oily liquid which remained was fractionally distilled under diminished pressure; after several fractionations, the greater part distilled at a constant temperature.

The alcohol, $\mathrm{C}_{9} \mathrm{H}_{15} \cdot \mathrm{OH}$, is a colourless, rather viscid liquid, with an odour somewhat like that of pinene. It boils at $147-148^{\circ}$ under a pressure of $90 \mathrm{~mm}$. It does not mix with water, but is freely soluble in alcohol or ether. It is unsaturated, uniting with two atomic proportions of bromine to form an additive compound, which, however, is unstable and quickly decomposes with evolution of hydrogen bromide :

$$
\begin{gathered}
0.3226 \text { gave } 0.9126 \mathrm{CO}_{2} \text { and } 0.3274 \mathrm{H}_{2} \mathrm{O} . \mathrm{C}=77 \cdot 1 ; \mathrm{H}=11 \cdot 4 . \\
0.3660 \Rightarrow 1.0362 \mathrm{CO}_{3}, 0.3776 \mathrm{H}_{2} \mathrm{O} . \mathrm{C}=77.2 ; \mathrm{H}=11.5 . \\
\mathrm{C}_{9} \mathrm{H}_{16} \mathrm{O} \text { requires } \mathrm{C}=77 \cdot 1 ; \mathrm{H}=11.4 \text { per cent. }
\end{gathered}
$$

The phenylurethane, $\mathrm{C}_{9} \mathrm{H}_{15} \mathrm{O} \cdot \mathrm{CO} \cdot \mathrm{NHPh}$, was obtained by heating the alcohol with phenylcarbimide and recrystallising the product several times from dilute alcohol. It crystallises in colourless, lustrous prisms, which melt at $96^{\circ}$, and is very readily soluble in alcohol or ether, but insoluble in water :

0.2658 gave 13.2 c.c. nitrogen at $18^{\circ}$ and $766 \mathrm{~mm} . \quad \mathrm{N}=5.8$.

$$
\mathrm{C}_{16} \mathrm{H}_{21} \mathrm{O}_{2} \mathrm{~N} \text { requires } \mathrm{N}=5 \cdot 4 \text { per cent. }
$$

Several different methods of preparing a benzoate and an acetate 
from the alcohol were tried, but satisfactory products were not obtained. On the other hand, a crystalline acid phthalic ester, $\mathrm{CO}_{2} \mathrm{H} \cdot \mathrm{C}_{6} \mathrm{H}_{4} \cdot \mathrm{CO}_{2} \cdot \mathrm{C}_{9} \mathrm{H}_{15}$, was easily produced. Equal weights of the alcohol and of finely-powdered phthalic anhydride were mixed with a little benzene and heated for some hours on the water-bath under a reflux condenser. The mixture was then poured into crushed ice, sodium carbonate was added in slight excess, and the insoluble portion removed by filtration. The filtrate was acidified with dilute sulphuric acid and shaken several times with ether. The ethereal solution was washed and dried, the ether removed by distillation, and the solid residue which remained was purified by several crystallisations from light petroleum.

The ester obtained in this way crystallises in silvery leaflets which melt at $107^{\circ}$. It is very readily soluble in alcohol or ether, sparingly so in light petroleum, and insoluble in water :

0.2398 gave $0.6246 \mathrm{CO}_{2}$ and $0.1598 \mathrm{H}_{2} \mathrm{O} . \quad \mathrm{C}=70.9 ; \mathrm{H}=7 \cdot 4$.

$$
\mathrm{O}_{17} \mathrm{H}_{20} \mathrm{O}_{4} \text { requires } \mathrm{C}=70.8 ; \mathrm{H}=6.9 \text { per cent. }
$$

When treated with cold aqueous sodium carbonate, it passes readily into solution, forming a colourless sodium salt.

\section{Preparation of the Amine, $\mathrm{C}_{9} \mathrm{H}_{15} \cdot \mathrm{NH}_{2}$.}

A mixture of the ketone with twice its weight of dry ammonium formate was heated in a sealed tube at $165^{\circ}$ for twelve hours. After cooling, the contents of the tube were extracted with water and with ether, the ethereal solution was separated, evaporated, and the residue, which consisted for the most part of the formyl derivative of the amine, was hydrolysed by heating with an alcoholic solution of potassium hydroxide under a reflux condenser for about fifteen hours. After adding water to the solution, the amine was extracted by means of ether, and then removed from the ethereal solution by agitation with dilute hydrochloric acid. The solution of the hydrochloride was mixed with excess of potassium hydroxide, and the liberated amine was distilled in a current of steam and extracted from the distillate with ether. The ethereal solution was dried with potassium hydroxide, and then saturated with dry hydrogen chloride. The crystalline precipitate of the hydrochloride of the amine which separated was purified by solution in alcohol and precipitation with ether, and from the pure salt the amine was obtained by addition of potassium hydroxide and distillation with steam.

The amine, $\mathrm{C}_{9} \mathrm{H}_{15} \cdot \mathrm{NH}_{2}$, is a colourless oily liquid with a strong disagreeable odour and an alkaline reaction. It is almost insoluble in water, but easily soluble in alcohol or ether, and it volatilises readily in steam. Unfortunately, the quantity of this compound obtained 
was too small to permit of the determination of its physical constants.

The hydrochloride of the amine, $\mathrm{C}_{9} \mathrm{H}_{15} \cdot \mathrm{NH}_{2}, \mathrm{HCl}$, crystallises in white, silky needles. It is extremely easily soluble in water or alcohol, but nearly insoluble in ether. On heating, it decomposes without melting, ammonium chloride being formed. The percentage of hydrogen chloride in the salt was determined, and the result agreed well with that required by the formula, although the quantity taken for analysis was of necessity very small.

The platinichloride of the amine, $\left(\mathrm{C}_{9} \mathrm{H}_{15} \cdot \mathrm{NH}_{2}\right)_{2}, \mathrm{H}_{2} \mathrm{PtCl}_{6}$, crystallises in pale yellow leaflets, and is fairly readily soluble in water :

0.2438 gave $0.0702 \mathrm{Pt}$. $\mathrm{Pt}=28 \cdot 8$.

$\mathrm{C}_{18} \mathrm{H}_{36} \mathrm{~N}_{2} \mathrm{Cl}_{6} \mathrm{Pt}$ requires $\mathrm{Pt}=28 \cdot 4$ per cent.

\section{Preparation of the Compound $\mathrm{C}_{10} \mathrm{H}_{15} \mathrm{OCl}$.}

The small quantities of a substance of higher boiling point, which were separated in the process of purifying several different preparations of the ketone, were mixed and subjected to fractional distillation under a pressure of $40 \mathrm{~mm}$. in an atmosphere of dry carbon dioxide. The portion which distilled at $160-165^{\circ}$ solidified on cooling to a pasty mass. From this product, the oily portion was separated as completely as possible by the aid of the pump, and the solid residue was drained on a porous plate, being then purified by several crystallisations from light petroleum. Further fractionations of the oily portion yielded an additional quantity of the crystalline compound.

The compound $\mathrm{C}_{10} \mathrm{H}_{15} \mathrm{OCl}$ is a snow-wbite, crystalline solid with a slight odour. It melts at $168^{\circ}$, and when heated above its melting point at atmospheric pressure it is decomposed with formation of water, hydrogen chloride, and oily substances. Slight decomposition also occurs when it is heated under diminished pressure, similar decomposition products being formed in small quantity. It is insoluble in water, but very readily soluble in alcohol, ether, or light petroleum :

$$
\begin{aligned}
& 0.2074 \text { gave } 0.4932 \mathrm{CO}_{2} \text { and } 0 \cdot 1508 \mathrm{H}_{2} \mathrm{O} . \quad \mathrm{C}=64 \cdot 7 ; \mathrm{H}=8 \cdot 1 . \\
& 0.2030 \Rightarrow 0 \cdot 1572 \mathrm{AgCl} . \quad \mathrm{Cl}=19 \cdot 1 . \\
& \mathrm{C}_{10} \mathrm{H}_{15} \mathrm{OCl} \text { requires } \mathrm{C}=64 \cdot 4 ; \mathrm{H}=8 \cdot 0 ; \mathrm{Cl}=19 \cdot 0 \text { per cent. }
\end{aligned}
$$

It was found that this chlorinated oxidation product did not yield either an oxime or a semicarbazone, at least under usual conditions, and that it is very inert towards a number of other reagents. It is not decomposed by boiling water, and is scarcely affected when heated with moist silver oxide, or with silver acetate in presence of alcohol, or with a concentrated alcoholic solution of potassium hydroxide. However, it is slowly attacked by sodium ethoxide in hot alcoholic solution, and 
the following method of treatment was adopted. Sodium was added gradually to a concentrated alcoholic solution of the compound, which was then boiled under a reflux condenser for a considerable period. Sodium chloride slowly separated, and, when the reaction appeared to be at an end, water was added and the mixture was shaken several times with ether. The ethereal solution was separated, washed with water, and dried with calcium chloride, and after removal of the ether there remained a yellow, crystalline solid with a very strong odour like that of camphor. As this substance was found still to contain some chlorine, the treatment with sodium and alcohol was repeated several times. Finally, the product, separated as described, was purified by distillation in a current of steam and by crystallisation from dilute alcohol. In this way, a small quantity of a compound which contained no chlorine was obtained. It crystallises in small colourless prisms, which melt at about $165^{\circ}$, and has a very strong odour, somewhat like that of camphor. It is very readily soluble in the usual organic solvents, and it volatilises very easily in a current of steam. The quantity in our hands was insufficient for analysis.

We desire to express our thanks to the Committee of the Carnegie Trust for a grant which defrayed the expenses, and to Mr. James D. Fraser for assistance in part of the work.

Chemistry Department, The Glasgow and West of Scotland Teghnical College. 